\title{
REVISÃO DE ESTUDOS SOBRE A RECUPERAÇÃO DE AMÔNIA VIA PRECIPITAÇÃO DE ESTRUVITA
}

\section{REVIEW OF STUDIES ON AMMONIA RECOVERY THROUGH STRUVITE PRECIPITATION}

\section{Letícia Mothé do Nascimento Rodrigues ${ }^{1}$, Raniella Falchetto Bazoni², \& Aloísio José Bueno Cotta ${ }^{3 *}$}
${ }^{1}$ Departamento de Engenharias e Tecnologia. ${ }^{23}$ Departamento de Ciências Naturais. Centro Universitário Norte do Espírito Santo da Universidade Federal do Espírito Santo.

${ }^{1}$ leticiamothe15@gmail.com² ranivni@hotmail.com ${ }^{3 *}$ aloisio.cotta@ufes.br

\section{ARTIGO INFO.}

\section{Recebido em: 15.01.2021}

Aprovado em: 10.03.2021

Disponibilizado em: 31.03.2021

\section{Palavras-chave:}

Estruvita; tratamento de efluentes; revisão.

\section{KEYWORDS:}

Struvite; wastewater treatment; review.

\author{
*Autor Correspondente: Cotta, A. J. B.
}

\section{RESUMO}

A precipitação da estruvita $\left(\mathrm{MgNH}_{4} \mathrm{PO}_{4} \cdot 6 \mathrm{H}_{2} \mathrm{O}\right)$, integrada ao tratamento de efluentes, é ambiental e economicamente atrativa. Nesta revisão, as publicações, mais citadas nos últimos 20 anos, dedicadas à recuperação de nutrientes a partir de efluentes, via precipitação da estruvita, foram identificadas. As condições operacionais (pH, proporção dos reagentes, tempo de reação e condições de agitação e matérias primas utilizadas) e resultados alcançados foram examinados, visando identificar os fatores controladores da eficiência do processo de recuperação de nutrientes. Para tal, foi realizada uma revisão na base Web of Science, com os termos (struvite, ammonium, recovery, nutriente, treatment) a fim de selecionar os artigos. A relevância e atualidade do tema foi percebida pelo grande número publicações recentes. No geral, os melhores resultados foram obtidos com $\mathrm{pH}$ 8,5-9,0 e um ligeiro excesso de $\mathrm{Mg}^{2+}$, a partir da magnésia $(\mathrm{MgO})$ industrial. O que além de aumentar o rendimento, reduz o custo do processo. Diferentemente dos ensaios com efluentes sintéticos, os trabalhos com efluentes reais destacam que a presença de $\mathrm{K}^{+}, \mathrm{Ca}^{2+}$ e $\mathrm{HCO}_{3}{ }^{-}$devem ser consideradas ao se ajustar as quantidades adicionadas de reagentes. Praticamente todos os trabalhos relataram que a recuperação da amônia é mais difícil e ocorre em percentuais inferiores à do $\mathrm{P}$. Destaca-se, que a avaliação agronômica da estruvita obtida revelou sua grande aplicabilidade como fertilizante de liberação lenta, o que viabiliza financeiramente o processo de reciclagem de nutrientes.

\begin{abstract}
The precipitation of struvite $\left(\mathrm{MgNH}_{4} \mathrm{PO}_{4} \cdot 6 \mathrm{H}_{2} \mathrm{O}\right)$, integrated with the treatment of effluents, is environmentally and economically attractive. In this review, the most cited publications (of the past 20 years) dedicated to recovering nutrients from effluents via struvite precipitation were identified. The operating conditions ( $\mathrm{pH}$, the proportion of reagents, reaction time and agitation conditions, and raw materials used) and results achieved were examined, aiming to identify the factors controlling the nutrient recovery process's efficiency. To this end, a review was carried out on the Web of Science database, with the terms (struvite, ammonium, recovery, nutrient, treatment) to select the articles. The relevance and timeliness of the theme were noticed by many recent publications. In general, the best results were obtained with $\mathrm{pH}$ 8.5-9.0 and a slight excess of $\mathrm{Mg}^{2+}$, from magnesia (industrial $\mathrm{MgO}$ ). Which, in addition to increasing the yield, reduces the cost of the process. In contrast to the tests with synthetic effluents, studies with real effluents highlight that the presence of $K^{+}$ $\left(\mathrm{Ca}^{2+}\right.$ and $\left.\mathrm{HCO}_{3}^{-}\right)$must be considered when adjusting the added quantities of reagents. Virtually all studies reported that ammonia recovery is more difficult and occurs in lower percentages than P. It is noteworthy that the agronomic evaluation of the struvite obtained revealed its great applicability as a slow-release fertilizer, which financially enables the nutrient recycling process.
\end{abstract}



precipitação de estruvita. Brazilian Journal of Production Engineering, 6(9), Edição Especial "Iniciação Científica", 20-36.

\section{INTRODUÇÃO}

A eutrofização dos corpos d'água é um grave problema decorrente da disposição inadequada de efluentes contendo nutrientes, nitrogênio e fósforo (Halling-Sørensen \& Jorgensen, 1993). A amônia $\left(\mathrm{NH}_{3}\right)$ é um importante traçador da contaminação nos corpos hídricos (Giordano et al., 2002). A concentração total de nitrogênio amoniacal corresponde à soma das espécies amônia $\left(\mathrm{NH}_{3}\right)$ e íon amônio $\left(\mathrm{NH}_{4}{ }^{+}\right)$, que se encontram em equilíbrio dinâmico no meio aquoso, Equação 1 (Camargo, 2012).

$$
\mathrm{NH}_{3(\mathrm{aq})}+\mathrm{H}^{+}{ }_{(\mathrm{aq})} \leftrightarrows \mathrm{NH}_{4}{ }^{+}{ }_{(\mathrm{aq})} \quad \text { (Equação 1) }
$$

Se comparada ao amônio, a amônia livre é mais tóxica, pois é capaz de permear a membrana celular dos peixes e vertebrados e de se acumular nos tecidos gordurosos ao ponto de causar desde alterações metabólicas, até a morte do organismo (Pereira \& Mercante, 2005; Cerna, 2008).

O descarte das águas residuais contendo nutrientes é considerado um "desperdício", pois ainda pode oportunizar a recuperação de recursos (Sikosana, Randall \& Blottnitz., 2017). A reciclagem de nutrientes é atrativa não apenas do ponto de vista ambiental e financeiro, como também propiciam uma agricultura mais sustentável, ao reduzir a demanda por água, energia e ao minimizar os impactos ambientais, associados a produção e uso de fertilizantes convencionais (Liu, Rahman \& Kwag, 2011).

$\mathrm{O}$ uso de nutrientes reciclados tem o potencial de melhorar à segurança alimentar, decorrente a depleção das reservas de rocha fosfatadas (Talboys et al., 2016), e está alinhada aos Objetivos de Desenvolvimento Sustentável (ODS) da Organização das Nações Unidas (ONU, 2015).

A maioria dos efluentes municipais e industriais, após digestão anaeróbia, e lixiviados de aterros sanitários são ricos em amônia (500 a $2.200 \mathrm{mg} / \mathrm{L})$ e, por isso, encontram grande dificuldades de tratamento por métodos biológicos, dada a toxidez do composto quando em concentrações acima de $200 \mathrm{mg} / \mathrm{L}$ (Uysal, Yilmazel \& Demirer, 2010). A Resolução $\mathrm{n}^{\circ}$ 430/2011, do Conselho Nacional de Meio Ambiente (CONAMA), estabelece o valor de 20 $\mathrm{mg} / \mathrm{L}$ como limite de $\mathrm{N}$-amoniacal total para o descarte de efluentes em cursos d'água (Ministério do Meio Ambiente [MMA], 2011). Nesse contexto, uma etapa intermediária de precipitação e/ou volatilização têm de ser incluída no processo de tratamento, seja para viabilizar o tratamento biológico ou para o enquadramento aos padrões de lançamento (Ledesma, 2014).

Entre as técnicas de recuperação de nutrientes para produção de fertilizante, a precipitação da estruvita $\left(\mathrm{MgNH}_{4} \mathrm{PO}_{4} 6 \mathrm{H}_{2} \mathrm{O}\right)$ ainda é pouco explorada industrialmente (Hostert et al., 2020). Para efluentes com alta concentração de $\mathrm{NH}_{3}\left(\right.$ ou $\left.\mathrm{NH}_{4}{ }^{+}\right)$, magnésio $\left(\mathrm{Mg}^{2+}\right)$ e fosfato $\left(\mathrm{H}_{\mathrm{n}} \mathrm{PO}_{4}{ }^{3-n}\right)$ são adicionados para formar da estruvita, Equação 2, (Hostert et al., 2020). A relação equimolar entre o ácido $\left(\mathrm{H}^{+}\right)$e a estruvita, é apresentada na Equação 3 (Celen \& Türker, 2001).

$$
\begin{gathered}
\mathrm{Mg}^{2+}+\mathrm{NH}_{4}^{+}+\mathrm{H}_{n} \mathrm{PO}_{4}^{3-{ }_{(a q)}} \leftrightarrows \mathrm{MgNH}_{4} \mathrm{PO}_{4} \cdot 6 \mathrm{H}_{2} \mathrm{O}+n \mathrm{H}^{+}{ }_{(\mathrm{aq})} \quad \text { (Equação 2) } \\
\mathrm{Mg}^{2+}+\mathrm{NH}_{4}^{+}+\mathrm{HPO}_{4}{ }^{2-}{ }_{(\mathrm{aq})} \leftrightarrows \mathrm{MgNH}_{4} \mathrm{PO}_{4} \cdot 6 \mathrm{H}_{2} \mathrm{O}+\mathrm{H}^{+}{ }_{(\mathrm{aq})} \quad \text { (Equação 3) }
\end{gathered}
$$

Munch e Barr (2001) destacaram que a eficiência da recuperação de nutrientes a partir de efluentes, via produção da estruvita, depende preponderantemente do ajuste das proporções 

precipitação de estruvita. Brazilian Journal of Production Engineering, 6(9), Edição Especial "Iniciação Científica", $20-36$.

entre seus constituintes $\left(\mathrm{Mg}^{2+} / \mathrm{NH}_{4}+/ \mathrm{PO}_{4}{ }^{3-}\right)$ e do controle do $\mathrm{pH}$, uma vez que a solubilidade da estruvita diminui com o aumento do $\mathrm{pH}$ entre 7 e 10. Além disso, a inclusão da etapa de precipitação, após o tratamento anaeróbio dos efluentes, é atrativo pela alta disponibilidade de $\mathrm{NH}_{4}{ }^{+}$e $\mathrm{PO}_{4}{ }^{3-}$ após a etapa de fermentação, o que evita a formação de incrustações no interior das tubulações que conduzem o efluente para as etapas seguintes do tratamento (Lei et al., 2006).

De acordo com Ueno \& Fujii (2001), o Japão domina a tecnologia de recuperação de $\mathrm{PO}_{4}{ }^{3-}$ a partir de efluentes desde o início de 1990, e possui companhias operando em escala industrial na produção e comercialização da estruvita. A qual é obtida com contaminação mínima de metais e poluentes orgânicos, além de ser de fácil manuseio, transporte e armazenamento (Battistoni et al., 2005).

A estruvita atua como fertilizante de liberação lenta, e por isso, permite que as plantas assimilem os nutrientes ao longo de seu desenvolvimento, o que minimiza o carreamento e problemas de fitotoxidez, geralmente, associados ao uso de fertilizantes comerciais (Bhuiyan et al., 2008). Memelli et al. (2018) revisaram diversos ensaios sobre a aplicação agronômica da estruvita como fertilizante e destacaram os bons resultados obtidos em uma ampla gama de culturas e solos.

Uma das principais dificuldades com a precipitação da estruvita é a formação de cristais pequenos (Forrest et al., 2008). Doyle et al. (2003) alertam que a viabilidade da produção de estruvita, e seu emprego como fertilizante, dependem da pureza e do tamanho dos cristais, sendo desejável a produção de grãos > 0,5 mm. Por isso, é extremamente importante que os reatores de síntese promovam uma alta taxa de conversão, e o crescimento dos cristais. A viabilidade financeira do processo de recuperação do $\mathrm{N}$, via cristalização da estruvita, foi demonstrada por Darwish et al. (2016) combinando o uso de fontes alternativas de $\mathrm{Mg}$ e P, de baixo custo, com a comercialização do produto.

Rahman et al. (2014) revisaram estudos sobre a recuperação de nutrientes a partir de efluentes, e apontou o ajuste da razão molar $\mathrm{Mg}^{+2} / \mathrm{NH}_{4}{ }^{+}$, do $\mathrm{pH}$, do tempo de reação e da temperatura de síntese como as variáveis críticas do processo de precipitação da estruvita, as quais devem ser otimizadas para cada tipo de efluente. Iaconi et al. (2010) destacaram a importância do ajuste das relações molares entre a amônia, os íons fosfato $\left(\mathrm{PO}_{4}{ }^{3-} / \mathrm{NH}_{4}{ }^{+}\right)$e o magnésio $\left(\mathrm{Mg}^{2+} / \mathrm{NH}_{4}{ }^{+}\right)$. Bouropoulos e Koutsoukos (2000) constataram que a taxa de diminuição do pH do meio reacional, durante a precipitação da estruvita (Equação 2), reflete na velocidade de formação dos cristais de estruvita. E apontou o controle do $\mathrm{pH}$ como determinante para alcançar um alto rendimento da reação.

Muitos estudos já foram realizados a fim de compreender o efeito dessas variáveis frente a precipitação da estruvita sob condições laboratoriais, em sua maioria com efluentes sintéticos, isto é, preparados a partir de reagentes de grau analítico (P.A.). Esta revisão concentra-se na identificação dos trabalhos científicos mais relevantes sobre a recuperação de nutrientes na forma de estruvita, no detalhamento da técnica de precipitação, e na comparação dos resultados obtidos durante o tratamento de efluentes reais em reatores de diferentes escalas.

\section{@ $\odot \Theta \odot$}




\section{OBJETIVo}

Identificar e revisar os artigos, com maior número de citações, sobre a precipitação da estruvita como forma de recuperação de nutrientes e assim verificar os fatores intervenientes sobre a eficiência do processo de tratamento de efluentes com reatores de diferentes escalas.

\section{Metodologia}

Foi realizada uma revisão sistemática da literatura especializada mediante pesquisa na base de dados Web of Science, com os termos (TS=((struvite) and (ammoniun or recovery or nutrient) and (treatment or effluent))), a fim de selecionar artigos em inglês que abordassem a recuperação da amônia em efluentes variados a partir da precipitação da estruvita e os fatores mais relevantes para o processo.

A busca realizada em 05/12/2020 com os termos identificou 770 artigos. As maiores ocorrências são das áreas de ciências e engenharia ambiental (Figura 1), com um recorde de 114 publicações em 2020 (Figura 2 ), com 384 ( $\approx 50 \%$ do total) ocorrendo nos 5 últimos anos. $\mathrm{O}$ que indica a relevância e a atualidade do tema.

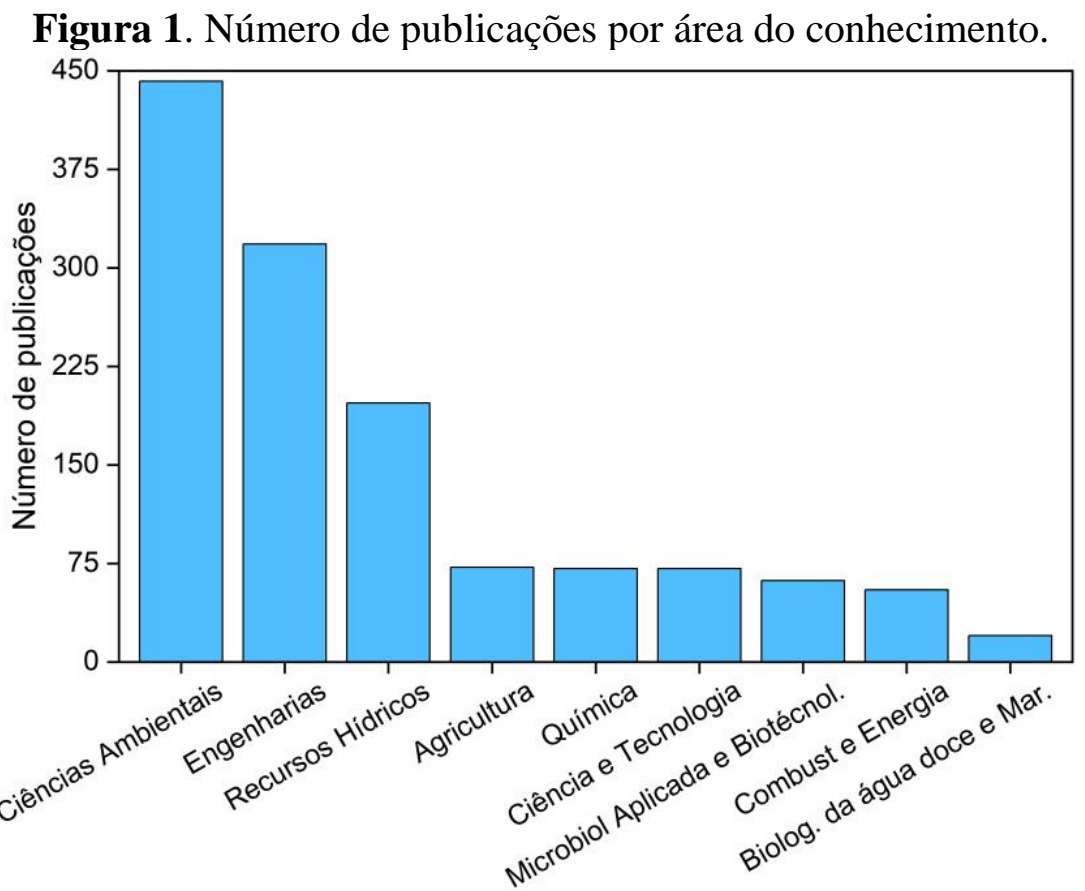

A China destaca-se como origem de 180 artigos (Figura 3), de 25 pesquisadores da Academia Chinesa de Ciências, a qual só é superada pela Universidade da Columbia Britânica (Canadá) com 26 publicações, e o autor (Mavinic, Donald S.) mais ativo com 20 publicações (Figura 4). 
Citação (APA): Rodrigues, L. M. do N., Bazoni, R. F, \& Cotta, A. J. B. (2021). Revisão de estudos sobre a recuperação de amônia via precipitação de estruvita. Brazilian Journal of Production Engineering, 6(9), Edição Especial "Iniciação Científica", 20-36.

Figura 2. Número de publicações por ano.

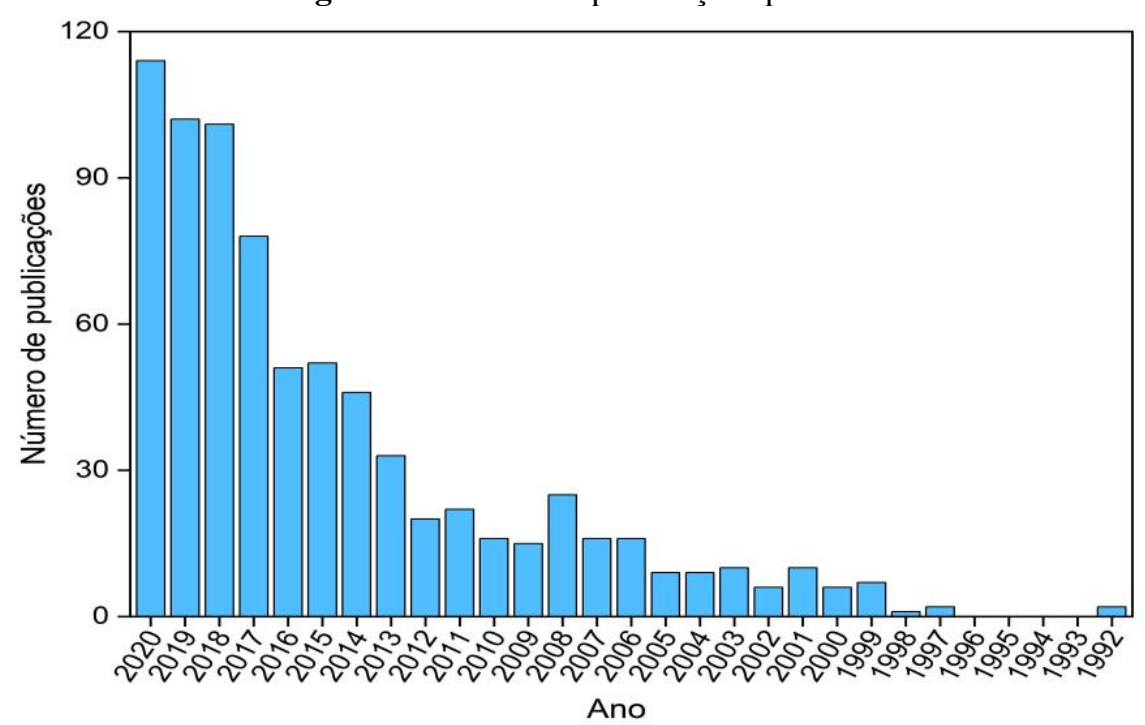

Figura 3. Número de publicações por país.

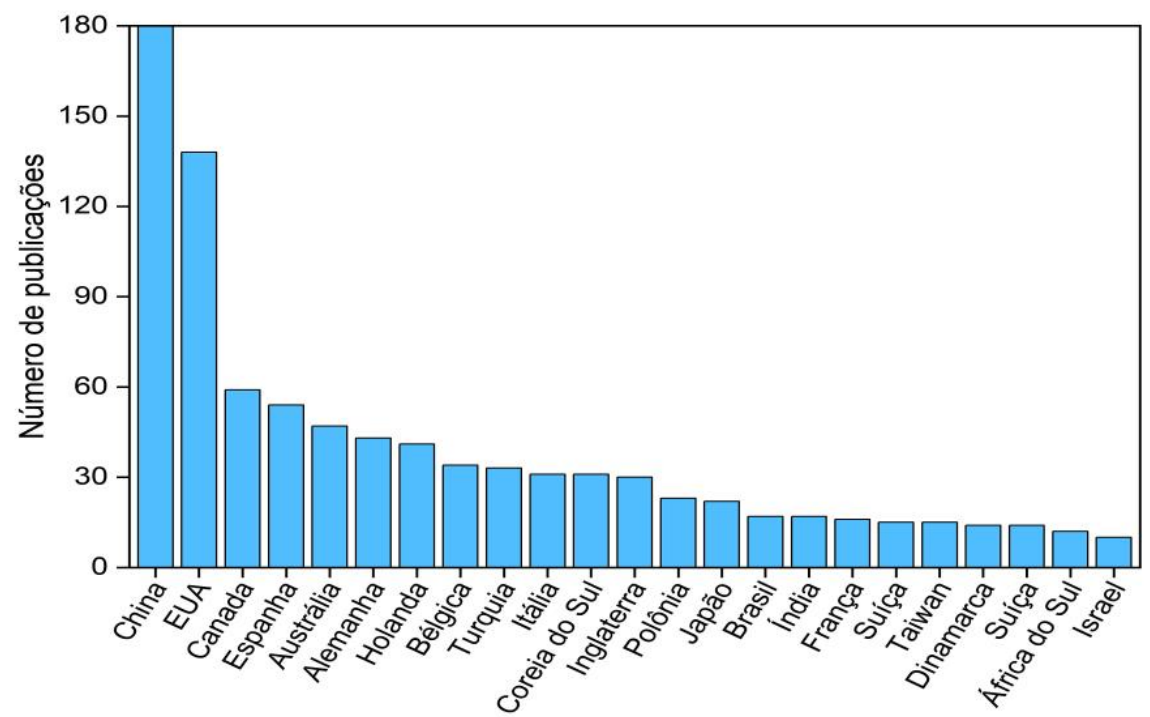

Figura 4. Número de publicações por autor.

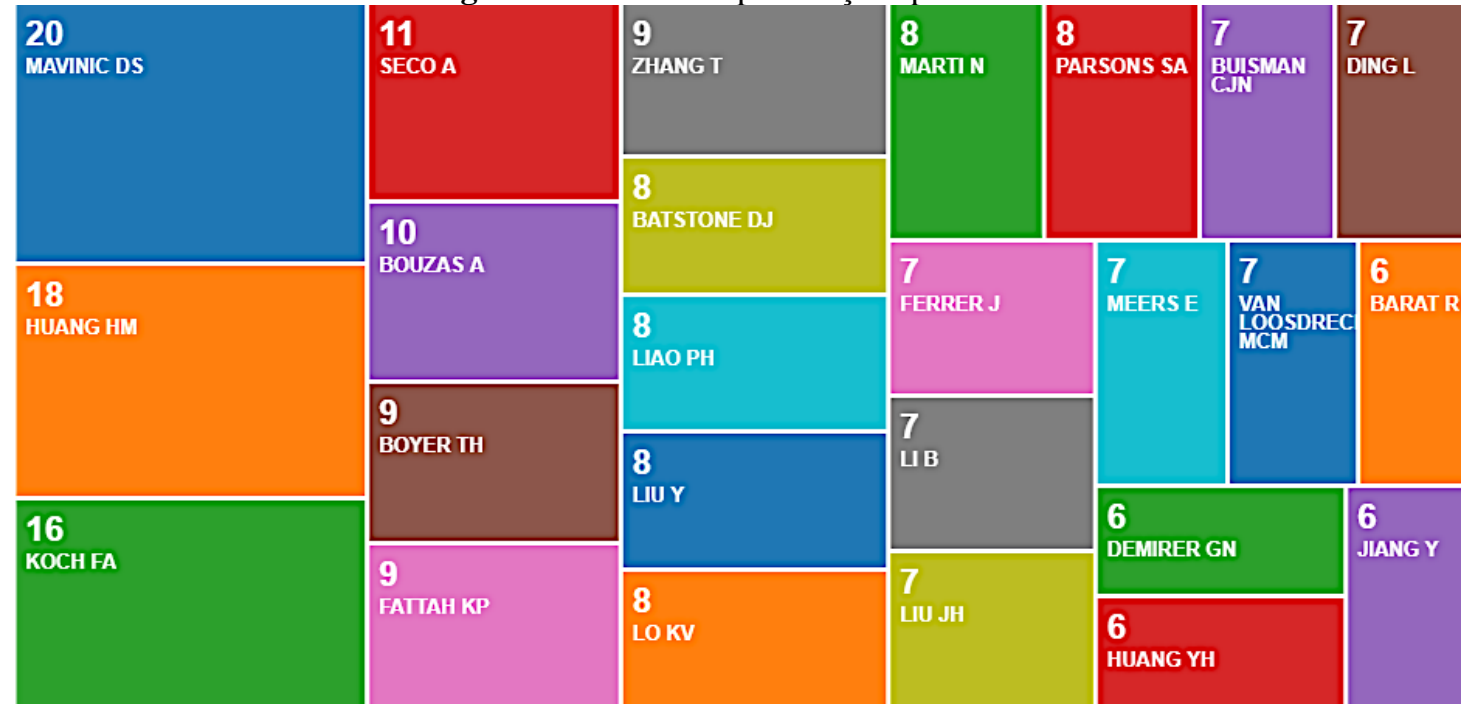



precipitação de estruvita. Brazilian Journal of Production Engineering, 6(9), Edição Especial "Iniciação Científica", $20-36$.

Os 770 identificados artigos foram ordenados segundo o número de citações e os resumos dos 30 artigos mais citados, publicados nos últimos 20 anos, foram avaliados e 10 estudos envolvendo o tratamento de efluentes com maior número de citações foram selecionados para esta revisão, Tabela 1. Os resultados de outros trabalhos também são examinados e discutidos para efeitos de comparação.

Tabela 1. Artigos selecionado para revisão com mais citações

\begin{tabular}{|c|c|c|c|}
\hline Título do artigo (DOI) & $\mathbf{1}^{\circ}$ autor & Ano & $\mathbf{N}^{\circ}$ citações \\
\hline $\begin{array}{c}\text { Struvite precipitation in anaerobic swine lagoon liquid: effect of } \\
\mathrm{pH} \text { and } \mathrm{Mg}: \mathrm{P} \text { ratio and determination of rate constant (DOI: } \\
10.1016 / \mathrm{S} 0960-8524(03) 00076-2)\end{array}$ & Nelson, N.O. & 2003 & 293 \\
\hline $\begin{array}{l}\text { Potential phosphorus recovery by struvite formation (DOI: } \\
10.1016 / \mathrm{S} 0043-1354(01) 00391-8)\end{array}$ & Jaffer, Y. & 2002 & 267 \\
\hline $\begin{array}{l}\text { Phosphate and potassium recovery from source separated urine } \\
\text { through struvite precipitation (DOI: } 10.1016 / \text { j.watres.2006.10.014) }\end{array}$ & Wilsenach, J.A. & 2007 & 264 \\
\hline $\begin{array}{l}\text { Low-cost struvite production using source-separated urine in Nepal } \\
\text { (DOI: } 10.1016 / \text { j.watres.2010.10.007) }\end{array}$ & Etter, B. & 2011 & 193 \\
\hline $\begin{array}{c}\text { Three years experience of operating and selling recovered struvite } \\
\text { from full-scale plant } \\
\text { (DOI: } 10.1080 / 09593332208618196)\end{array}$ & Ueno, Y. & 2001 & 168 \\
\hline $\begin{array}{c}\text { Recovery of ammonium nitrogen from the effluent of UASB } \\
\text { treating poultry manure wastewater by MAP precipitation as a } \\
\text { slow release fertilizer } \\
\text { (DOI: } 10.1016 / \text { j.jhazmat.2008.11.025) }\end{array}$ & Yetilmezsoy, K. & 2009 & 167 \\
\hline $\begin{array}{c}\text { The determination of fertilizer quality of the formed struvite from } \\
\text { effluent of a sewage sludge anaerobic digester (DOI: } \\
\text { 10.1016/j.jhazmat.2010.05.004) }\end{array}$ & Uysal, A. & 2010 & 158 \\
\hline $\begin{array}{l}\text { Ammonia removal from anaerobically digested dairy manure by } \\
\text { struvite precipitation (DOI: } 10.1016 / \text { j.procbio. } 2005.02 .028 \text { ) }\end{array}$ & Uludag-Demirer, S. & 2005 & 149 \\
\hline $\begin{array}{c}\text { Recovery of ammonia nitrogen from industrial wastewater } \\
\text { treatment as Struvite slow releasing fertilizer (DOI: } \\
10.1016 / \text { j.desal.2006.08.019) }\end{array}$ & Diwani, G. & 2007 & 130 \\
\hline $\begin{array}{l}\text { Removal of ammonium and phosphates from wastewater resulting } \\
\text { from the process of cochineal extraction using MgO-containing by- } \\
\text { product (DOI: } 10.1016 / \mathrm{S} 0043-1354(02) 00526-2)\end{array}$ & Chimenos, J. M. & 2003 & 121 \\
\hline
\end{tabular}

Para facilitar a comparação das condições de precipitação e a discussão deste trabalho, as concentrações dos constituintes da estruvita informadas nos artigos em unidades diversas (mg/l e $\mathrm{m}$ mol/l) foram recalculadas e padronizadas na forma de razões molares $\left(\mathrm{Mg}^{2+} / \mathrm{NH}_{4}+/ \mathrm{PO}_{4}{ }^{3-}\right)$.

\section{RESULTADOS}

\section{REVISÃO BIBLIOGRÁFICA}

O trabalho mais citado, Nelson et al. (2003), promoveu o tratamento de efluente de suinocultura após estabilização em lagoa anaeróbia. A publicação destaca que a conversão dos nutrientes em estruvita é atrativa, frente à aplicação direta do efluente nas lavouras. Isto por que o uso da estruvita implica na oferta de nutrientes $\left(\mathrm{PO}_{4}{ }^{3-}: \mathrm{NH}_{4}{ }^{+}\right)$na proporção $1: 1$, ao passo que o efluente possui $\mathrm{P}$ em excesso (3:1). E por isso, se usado na fertirrigação promoveria a eutrofização dos cursos d'água. As melhores condições de precipitação identificadas (pH entre 8,9 e 9,2, com razão molar $\mathrm{Mg}^{2+} / \mathrm{NH}_{4}{ }^{+} / \mathrm{PO}_{4}{ }^{3-}$ de $\left.1,6 / 1,0 / 1,0\right)$ permitiram recuperar $90 \%$ do $\mathrm{P}$ e $\mathrm{N}$ do efluente em reator de 1,1 litro com agitação mecânica. Já o tratamento com apenas $10 \%$ de excesso estequiométrico de $\mathrm{Mg}^{2+}$ (razão de 1,1/1,0/1,0) fixou 80\% dos nutrientes na forma de estruvita, o que reflete a maior eficiência de precipitação alcançada com maiores doses de $\mathrm{Mg}^{2+}$. Os autores não deixaram claro se consideraram a presença de 350 a $664 \mathrm{mg} / \mathrm{L}$ de $\mathrm{K}^{+}$nos efluentes avaliados ao estimar as quantidades de reagentes a serem adicionados durante o tratamento.

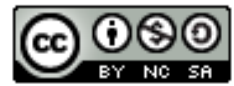



precipitação de estruvita. Brazilian Journal of Production Engineering, 6(9), Edição Especial "Iniciação Científica", 20-36.

Entretanto, os altos percentuais de remoção de amônia indicam que a presença do $\mathrm{K}^{+}$foi considerada e as quantidades de reagentes ajustadas para fazer a precipitação da estruvita $\left(\mathrm{MgNH}_{4} \mathrm{PO}_{4}\right)$ e de seu análogo potássico $\left(\mathrm{MgKPO}_{4} \cdot 6 \mathrm{H}_{2} \mathrm{O}\right)$. Segundo os autores, o processo de precipitação segue o modelo de $1^{\circ}$ ordem e completa em menos 30 min independentemente das condições de síntese.

Kim et al. (2017) destacaram que o efluente de suinocultura, após tratamento em reator anaeróbio, é rico em amônia (razão molar $\mathrm{Mg}^{2+} / \mathrm{NH}_{4}+/ \mathrm{PO}_{4}{ }^{3-}$ de $1,0 / 75 / 1,8 ; \mathrm{NH}_{4}{ }^{+}=1.859 \mathrm{mg} / \mathrm{L}$ ) e que o tratamento em $\mathrm{pH}$ entre 8,0 e 10, em reator de bancada (5L, com 3 horas de tempo de detenção hidráulica-TDH), sob agitação mecânica, com adição de reagentes P.A. $\left(\mathrm{MgCl}_{2} \cdot 6 \mathrm{H}_{2} \mathrm{O}\right.$ e $\mathrm{KH}_{2} \mathrm{PO}_{4}$ ) para obter razões de 1,2/1,1/1,0, permite altos percentuais de recuperações de amônia (90\%) em efluente sintético, porém apenas $40 \%$ de remoção no efluente real. Para o $\mathrm{PO}_{4}{ }^{3-}$, a remoção variou de 90 a 95\% em ambos efluentes. Kim et al. (2017) justificaram a menor remoção de amônia devido ao consumo de reagentes $\left(\mathrm{Mg}^{2+}\right.$ e $\left.\mathrm{PO}_{4}{ }^{3-}\right)$ com a precipitação da estruvita potássica, provavelmente pela alta concentração de $\mathrm{K}^{+}$no efluente (valor não informado). O trabalho de Kim et al. (2017) tem apenas 24 citações, mas devido a sua abrangência e profundidade dos resultados foi incluído nesta revisão.

Os bons resultados alcançados por Uludag-Demier et al. (2005), com 95\% recuperação da amônia, ao tratar o efluente gerado pela digestão anaeróbia de esterco bovino, superam a eficiência reportada por Nelson et al. (2003), com esterco suíno, ambos após estabilização por metanogênese. A maior remoção de amônia se deve ao uso do excesso estequiométrico, tanto de $\mathrm{PO}_{4}{ }^{3-}$ e de $\mathrm{Mg}^{2+}$, a partir de reagentes $\mathrm{Na}_{2} \mathrm{HPO}_{4}$ e $\mathrm{MgCl}_{2} .6 \mathrm{H}_{2} \mathrm{O}$, o qual foi mais efetivo do que $\mathrm{Mg}(\mathrm{OH})_{2}$, para a precipitação da estruvita realizada em $\mathrm{pH}=8,50 . \mathrm{O} \mathrm{pH}$ do meio reacional se estabilizou em menos de $30 \mathrm{~min}$, indicando o fim da precipitação, e a produção um efluente tratado com menos de $10 \mathrm{mg} / \mathrm{L}$ de amônia, porém as custas de um alto consumo de reagentes $\left(\mathrm{Mg}^{2+} / \mathrm{NH}_{4}+\approx 2,2\right)$. A operação com um menor excesso $\left(\mathrm{Mg}^{2+} / \mathrm{NH}_{4}{ }^{+} \approx 1,3\right)$ alcançou $90 \%$ de remoção de amônia.

Com base em três anos de experiência no tratamento de efluente municipal por digestão anaeróbia, seguido da precipitação da estruvita em reatores de leito fluidizado de 500 e 150 $\mathrm{m}^{3} /$ dia (em $\mathrm{pH} \approx 8,5 \pm 0,3$, com razão molar 1,3/1,0/1,0), Ueno \& Fujii (2001) obtiveram cristais alongados de 0,5 a 1,0 mm após 10 dias de recirculação dos grãos menores até sua sedimentação no tanque de decantação. A remoção de $\mathrm{NH}_{3}$ não foi informada, mas a de $\mathrm{PO}_{4}{ }^{3-}$ alcançou $90 \%$. Em seu trabalho, os autores destacaram que a estruvita produzida $(\approx 500 \mathrm{~kg} / \mathrm{dia})$ incorporou apenas quantidades diminutas de elementos tóxicos ( $\mathrm{As}, \mathrm{Cd}, \mathrm{Cr}, \mathrm{Pb}, \mathrm{Hg}$ e $\mathrm{Ni}$ ) e que é vendida como fertilizante de liberação lenta, para reforçar a viabilidade econômica do processo.

O segundo trabalho mais citado, Jaffer et al. (2002), também estudou a recuperação de nutrientes a partir de esgoto municipal após digestão anaeróbia e centrifugação para concentração do líquido. O processo objetivava a produção da estruvita antes de sua precipitação no interior das tubulações da estação de tratamento, evitando assim períodos de inatividade e custos com manutenção. Um reator de leito fluidizado, de pequena escala (TDH de $3 \mathrm{~h}$, fluxo de $20 \mathrm{~mL} / \mathrm{min})$, foi empregado no tratamento do efluente $\left(\mathrm{Mg}^{2+} / \mathrm{NH}_{4}{ }^{+} / \mathrm{PO}_{4}{ }^{3-}\right.$ de $1,0 / 19 / 1,7 ; \mathrm{NH}_{4}{ }^{+}=615 \mathrm{mg} / \mathrm{L}$, com $\left.\mathrm{Ca}^{2+} / \mathrm{Mg}^{2+}=0,8\right)$, o qual recebeu $\mathrm{NaOH}$ para ajuste do $\mathrm{pH}$ 

precipitação de estruvita. Brazilian Journal of Production Engineering, 6(9), Edição Especial "Iniciação Científica", 20-36.

em 9,0 e $\mathrm{MgCl}_{2} .6 \mathrm{H}_{2} \mathrm{O}$ para obter uma razão $\mathrm{Mg}^{2+} / \mathrm{PO}_{4}{ }^{3-}$ de 1,05. Essa condição permitiu recuperar $95 \%$ do fosfato, mas apenas $50 \%$ da amônia. Maiores adições de $\mathrm{Mg}^{2+}$ promoveram apenas a remoção de fosfato, pois fases distintas da estruvita eram precipitadas. A formação de hidroxiapatita $\left(\mathrm{Ca}_{5}\left(\mathrm{PO}_{4}\right)_{3}(\mathrm{OH})\right)$, apenas com o ajuste do $\mathrm{pH}(\approx 9,0)$, também contribui para recuperação do $\mathrm{P}$, mas sem remoção de amônia. Os autores estimaram uma produção diária de $231 \mathrm{~kg}$ de estruvita (ou 84 T/ano), cuja venda somada à economia com a redução dos gastos de manutenção pode viabilizar a inclusão da etapa de precipitação ao tratamento.

Uysal et al. (2010) foram capazes de recuperar $85 \%$ da amônia e 95\% do fosfato a partir do efluente de um digestor anaeróbio de lodo de esgoto municipal. $\mathrm{O}$ processo foi realizado com alíquotas de $250 \mathrm{~mL}$ do efluente $\left(\mathrm{NH}_{4}{ }^{+}=749 \mathrm{mg} / \mathrm{L}, \mathrm{NH}_{4}+/ \mathrm{Ca}^{2+} / \mathrm{K}^{+} / \mathrm{Mg}^{2+} / \mathrm{PO} 4^{3-} \approx\right.$ 48/3,1/3,4/1,0/1,9), adicionadas a beckers de $400 \mathrm{~mL}$, e mantidos sob agitação magnética (250 rpm) por $30 \mathrm{~min}$, com pH ajustado para 9,0 após a adição de $\mathrm{MgCl}_{2} \cdot 6 \mathrm{H}_{2} \mathrm{O}$ e $\mathrm{H}_{3} \mathrm{PO}_{4}$ para obter $\mathrm{Mg}^{2+} / \mathrm{PO}_{4}{ }^{3-} / \mathrm{NH}_{4}{ }^{+}$de $1,0 / 1,0 / 1,0$. A remoção de amônia alcançou $89 \%$ com maiores doses de $\mathrm{Mg}^{2+}\left(\mathrm{Mg}^{2+} / \mathrm{PO}_{4}{ }^{3-} / \mathrm{NH}_{4}{ }^{+} \approx 1,5 / 1,0 / 1,0\right)$. As quantidades adicionadas consideraram a presença dos interferentes $\mathrm{Ca}^{2+}$ e $\mathrm{K}^{+}$no efluente. $\mathrm{O}$ estudo demonstrou que a variação do $\mathrm{pH}$ de 8,5 para 9,0 não interfere na remoção de amônia, mas produz uma redução de $50 \%$ na concentração de fosfato residual. Por isso, o tratamento em $\mathrm{pH}=9,0$ foi indicado, mesmo sendo a remoção adicional do $\mathrm{P}$, decorrente da precipitação de fosfato de cálcio. A estruvita obtida (predominantemente na forma $\mathrm{MgNH}_{4} \mathrm{PO}_{4} \cdot 6 \mathrm{H}_{2} \mathrm{O}$ ) se mostrou livre de contaminação de elementos tóxicos e PCBs (bifenilas policloradas) presentes no efluente tratado e, portanto, pode ser utilizada como fertilizante.

Tanto a estruvita de amônia, quanto a de potássio foram obtidas durante o tratamento de urina $\left(\mathrm{Mg}^{2+} / \mathrm{PO}_{4}{ }^{3-} / \mathrm{NH}_{4}{ }^{+} / \mathrm{K}^{+}\right.$de $1,0 / 18 / 260 / 16 ; \mathrm{NH}_{4}{ }^{+} \mathrm{e} \mathrm{Ca}^{2+}=7.500$ e $176 \mathrm{mg} / \mathrm{L}$, respectivamente $)$ em $\mathrm{pH}=9,0 \pm 0,2$ com adição de $\mathrm{MgO}$ e $\mathrm{MgCl}_{2} .6 \mathrm{H}_{2} \mathrm{O}$ (reagentes P.A.) para obter $\mathrm{Mg}^{2+} / \mathrm{PO}_{4}{ }^{3-}=1,0$, em reator de 1,5 L, com agitação mecânica, e sistema especialmente projetado para separar o efluente tratado dos cristais formados (Wilsenach et al., 2007). O uso da magnésia (MgO), Equação 4, apresenta a vantagem de fornecer íons $\mathrm{Mg}^{2+}$, ao passo que também atua na elevação do pH (eliminando a necessidade de adição de base) e na neutralização da acidez gerada durante a formação da estruvita (Equações 2 e 3).

A alta concentração inicial de amônia na urina permitiu remover $96 \%$ do P, com TDH de $2 \mathrm{~h}$, independentemente da presença de $\mathrm{K}^{+}$e da velocidade de agitação (50 a $600 \mathrm{rpm}$ das hélices axiais). A remoção de amônia foi inferior a $65 \%$, em parte devido a formação da K-estruvita, mesmo com $\mathrm{NH}_{4}+\mathrm{K}^{+} \approx 16$. O comprimento dos cristais formados variou de 0,1 a $1 \mathrm{~mm}$.

$$
\underset{\text { Magnésia }}{\mathrm{MgO}_{(\mathrm{s})}}+\mathrm{H}_{2} \mathrm{O} \leftrightarrows \underset{\text { brucita }}{\mathrm{Mg}(\mathrm{OH})_{2(\mathrm{~s})}} \text { (Equação 4) }
$$

Etter et al. (2011) também se dedicaram à recuperação de nutrientes a partir da urina $\left(\mathrm{Mg}^{2+} / \mathrm{PO}_{4}{ }^{3-} / \mathrm{NH}_{4}{ }^{+} / \mathrm{K}^{+}\right.$de $1,0 / 8,0 / 15 / 32 ; \mathrm{NH}_{4}{ }^{+}$e $\mathrm{Ca}^{2+}=418$ e $\left.74 \mathrm{mg} / \mathrm{L}\right)$ de residentes de comunidades do Nepal. Os estudos foram realizados em dois reatores de $50 \mathrm{~L}$ de baixo custo, um com separação por filtração e outro por sedimentação. O resíduo de salmora, chamado "bittern" com 27,5g de Mg/L foi obtido localmente sem custo, e usado na precipitação. As

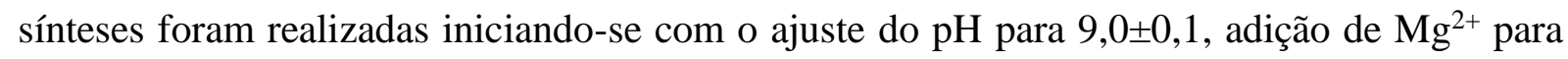
alcançar $\mathrm{Mg}^{2+} / \mathrm{PO}_{4}{ }^{3-}=1,1$, e 10 min de agitação manual, seguido de 1 a 6 h de sedimentação. $\mathrm{O}$ 

precipitação de estruvita. Brazilian Journal of Production Engineering, 6(9), Edição Especial "Iniciação Científica", $20-36$.

reator de filtração promoveu remoção de $91 \%$ do $\mathrm{P}$, em apenas $1 \mathrm{~h}$. Ao passo que problemas operacionais limitam a remoção com o reator de sedimentação a 50\%, além de apresentar problemas de incrustação da estruvita nas paredes. A estruvita obtida (provavelmente uma mistura de K-estruvita e $\mathrm{NH}_{4}{ }^{+}$-estruvita, não foi feita análise de difração de raios-X (DRX) para confirmação) pôde ser facilmente granulada para $2 \mathrm{~mm}$. Porém, a viabilidade econômica do tratamento depende da capacidade do reator (idealmente de $500 \mathrm{~L}$, operado com 8 ciclos/dia), da logística de transporte, de apoio governamental em reconhecimento à prestação de serviço coleta, tratamento e destinação de resíduos promovidos pelo projeto, e ainda do reaproveitamento do efluente tratado na fertirrigação.

"Bittern" também foi empregado por Diwani et al. (2007) com fonte alternativa de $\mathrm{Mg}^{2+}$, para o tratamento de efluente industrial $\left(\mathrm{Mg}^{2+} / \mathrm{PO}_{4}{ }^{3-} / \mathrm{NH}_{4}{ }^{+} / \mathrm{K}^{+}=1,0 / 27 / 643 / 11 ; \mathrm{NH}_{4}{ }^{+}\right.$e Ca ${ }^{2+}=2.652$ e $33 \mathrm{mg} / \mathrm{L}$ ). A adição de "bittern" e $\mathrm{KH}_{2} \mathrm{PO}_{4}$ para alcançar uma proporção equimolar entre os constituintes da estruvita permitiu recuperar apenas $36 \%$ da amônia em pH entre 8,6 e 9,6. Os autores demonstraram que o uso da estruvita como fertilizantes de liberação lenta, frente ao fertilizante convencional, aumentou o peso da planta de fava (da família das Fabaceae) e a absorção de NPK ao longo dos diferentes estágios de crescimento. E concluíram que a estruvita é capaz de manter os nutrientes prontamente disponíveis para absorção, o que implica em plantas mais saudáveis.

A água residuária do processo de produção do corante vermelho de carmim (ácido carmínico, E120) contém altos níveis de nutrientes $\left(\mathrm{PO}_{4}{ }^{3-}\right.$ e $\mathrm{NH}_{4}{ }^{+}=3.490$ e $\left.2.320 \mathrm{mg} / \mathrm{L}\right)$ e seu tratamento foi estudado por Chimenos et al. (2003). Magnésia (MgO) industrial, com $70 \%$ de pureza, foi utilizada como material alternativo para reduzir os custos do processo. A dose de $6,6 \mathrm{~g} / \mathrm{L}$ de $\mathrm{MgO}\left(\mathrm{Mg}^{2+} / \mathrm{PO}_{4}{ }^{3-} \approx 1\right)$ foi ajustada considerando a recuperação do fosfato, uma vez que este atua como reagente limitante $\left(\mathrm{NH}_{4}{ }^{+} / \mathrm{PO}_{4}{ }^{3-} \approx 4\right)$ no processo de precipitação da estruvita a partir deste tipo de efluente. No entanto, doses de $12 \mathrm{~g} / \mathrm{L}\left(\mathrm{Mg}^{2+} / \mathrm{PO}_{4}{ }^{3-} \approx 1,8\right)$ tiveram de ser empregadas para alcançar remoções de $97 \%$ de fosfato e $70 \%$ da amônia, com um tempo de reação de $24 \mathrm{~h}$ sob agitação, a qual foi necessária para completar a lenta hidratação da $\mathrm{MgO}$ em $\mathrm{Mg}(\mathrm{OH})_{2}$, Equação 4. Maiores doses de $20 \mathrm{~g} / \mathrm{L}\left(\mathrm{Mg}^{2+} / \mathrm{PO}_{4}{ }^{3-} \approx 3,0\right)$ elevaram discretamente as recuperações, 99 e 78\%, respectivamente, dentro de 6 h. A viabilidade econômica do processo permitiu sua inclusão às etapas de tratamento realizadas na planta industrial geradora do efluente. Os autores destacam que acima de $\mathrm{pH}$ 9,2 ocorrem significativas perdas de amônia devido a volatilização, o que pode ser explorado para completar o tratamento do efluente após a recuperação altamente eficiente do $\mathrm{P}$.

Uma alta recuperação de amônia $(85,4 \%)$, a partir de águas residuais geradas pelo tratamento de esterco de aves em reator anaeróbio (UASB), foi reportada por Yetilmezsoy \& Sapci-Zengin (2009) mediante a precipitação de estruvita, em $\mathrm{pH}=9,0$, após adição de $\mathrm{MgCl}_{2} .6 \mathrm{H}_{2} \mathrm{O}$ e $\mathrm{KH}_{2} \mathrm{PO}_{4}$ ao efluente $\left(\mathrm{NH}_{4}+\mathrm{PO}_{4}{ }^{3-}=6,1, \mathrm{NH}_{4}{ }^{+}=1.318 \mathrm{mg} / \mathrm{L}\right)$ para alcançar razão molar $\left(\mathrm{Mg}^{2+} / \mathrm{NH}_{4}{ }^{+} / \mathrm{PO}_{4}{ }^{3-}\right)$ unitária, sob agitação magnética por $15 \mathrm{~min}$, seguido de 30 min de sedimentação. $\mathrm{O}$ controle do $\mathrm{pH}$ se mostrou crítico para maximizar a eficiência do tratamento e para melhorar a sedimentação da estruvita. Os autores também verificaram que aumentos na proporção de $\mathrm{Mg}^{2+}$ e/ou $\mathrm{PO}_{4}{ }^{3-}$ não promovem maiores remoções de amônia e alertam para necessidade de tratamento adicional para reduzir a concentração de amônia residual, à qual é 
Citação (APA): Rodrigues, L. M. do N., Bazoni, R. F, \& Cotta, A. J. B. (2021). Revisão de estudos sobre a recuperação de amônia via precipitação de estruvita. Brazilian Journal of Production Engineering, 6(9), Edição Especial "Iniciação Científica", $20-36$.

baixa o suficiente para tratamento biológico. O cultivo de gramínea e de plantas ornamentais (agrião de jardim e baldroega) com a estruvita obtida levou a ganhos de massa (seca e úmida) 28 a $402 \%$ superiores ao alcançado nas plantas controle. A composição do efluente e as condições de tratamento são resumidas na Tabela 2.

Tabela 2. Resumo das condições operacionais e resultados alcançados

\begin{tabular}{|c|c|c|c|c|c|c|c|}
\hline Efluente & & eagentes & $\begin{array}{l}\text { Razão molar } \\
{\left[\mathrm{g}^{+2} / \mathrm{NH}_{4}+/ \mathrm{PO}_{4}{ }^{-3}\right.} \\
\end{array}$ & pH & Condições & Remoção & Autores \\
\hline $\begin{array}{l}\text { Suinocultura } \\
(51 \mathrm{mg} / \mathrm{l} \\
\left.\mathrm{PO}_{4}^{3-}\right)\end{array}$ & & $\mathrm{gCl}_{2} .6 \mathrm{H}_{2} \mathrm{O}$ & $1,6 / 1,0 / 1,0$ & $8,9-9,2$ & $\begin{array}{c}\text { Reator de bancada de } 1,1 \mathrm{~L} \\
\text { com agitação mecânica e } \\
4 \text { h de TDH }\end{array}$ & $\begin{array}{l}90 \% \mathrm{NH}_{4}{ }^{+} \mathrm{e} \\
\mathrm{PO}_{4}^{3-}\end{array}$ & $\begin{array}{l}\text { Nelson } \text { et } \\
\text { al. }(2003)\end{array}$ \\
\hline $\begin{array}{c}\text { Suinocultura } \\
(1.859 \mathrm{mg} / \mathrm{l} \\
\left.\text { de } \mathrm{NH}_{4}^{+}\right) \\
\end{array}$ & $\begin{array}{l}\mathrm{MgC} \\
\mathrm{e} \mathrm{KH}\end{array}$ & $\begin{array}{l}\mathrm{gCl}_{2} \cdot 6 \mathrm{H}_{2} \mathrm{O} \\
\mathrm{KH}_{2} \mathrm{PO} 4 \mathrm{O}_{4}\end{array}$ & $1,2 / 1,1 / 1,0$ & $8-10$ & $\begin{array}{c}\text { Reator de bancada de } 5 \mathrm{~L} \\
\text { com agitação mecânica e } \\
3 \mathrm{~h} \text { de TDH }\end{array}$ & $\begin{array}{l}40 \% \mathrm{NH}_{4}^{+} \\
95 \% \mathrm{PO}_{4}^{3-}\end{array}$ & $\begin{array}{l}\text { Kim et al. } \\
\text { (2017) }\end{array}$ \\
\hline $\begin{array}{c}\text { Suinocultura } \\
(1.410 \mathrm{mg} / \mathrm{l} \\
\left.\mathrm{de}^{\mathrm{NHH}} 4^{+}\right)\end{array}$ & & $\begin{array}{l}\mathrm{NaOH} \mathrm{e} \\
\mathrm{gCl}_{2} \cdot 6 \mathrm{H}_{2} \mathrm{O}\end{array}$ & $1,0 / 14 / 1,0$ & 8,5 & $\begin{array}{l}\text { Reator de bancada de } 1 \mathrm{~L} \\
\text { com agitação magnética }\end{array}$ & $\begin{array}{l}42 \% \mathrm{NH}_{4}^{+} \\
94 \% \mathrm{PO}_{4}^{3-}\end{array}$ & $\begin{array}{l}\text { Celen } \text { et al. } \\
\quad(2007)\end{array}$ \\
\hline 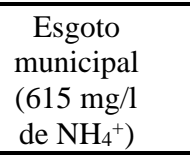 & $\mathrm{MgC}$ & $\mathrm{Cl}_{2} \cdot 6 \mathrm{H}_{2} \mathrm{O}$ & $1,05 / 1,1 / 1,0$ & 9,0 & $\begin{array}{l}\text { Reator de leito fluidizado de } \\
\text { pequena escala, } 20 \mathrm{~mL} / \mathrm{min} \text { e } \\
33 \mathrm{~h} \text { de TDH }\end{array}$ & $\begin{array}{l}50 \% \mathrm{NH}_{4}^{+} \\
95 \% \mathrm{PO}_{4}{ }^{3-}\end{array}$ & $\begin{array}{l}\text { Jaffer } e t \\
\text { al. }(2002)\end{array}$ \\
\hline $\begin{array}{c}\text { Urina } \\
\text { humana } \\
(7.500 \mathrm{mg} / \mathrm{l} \\
\left.\mathrm{NH}_{4}^{+}\right) \\
\end{array}$ & & $\mathrm{MgO}$ & $1,0 / 1,0 / 1,0$ & $9,0 \pm 0,2$ & $\begin{array}{l}\text { Reator de bancada de } 1,5 \mathrm{~L} \\
\text { com agitação mecânica de } \\
50-600 \text { rpm, } 2 \text { h de TDH }\end{array}$ & $\begin{array}{l}65 \% \mathrm{NH}_{4}^{+} \\
96 \% \mathrm{PO}_{4}{ }^{3-}\end{array}$ & $\begin{array}{l}\text { Wilsenac } \\
\text { h et al. } \\
\text { (2007) }\end{array}$ \\
\hline $\begin{array}{l}\text { Urina humana } \\
(418 \mathrm{mg} / 1 \\
\left.\mathrm{NH}_{4}^{+}\right)\end{array}$ & & Bittern & $1,1 / 1,0 / 1,0$ & $9,0 \pm 0,1$ & $\begin{array}{l}\text { Reator com separação por } \\
\text { filtros; } 50 \mathrm{~L} / 1 \mathrm{~h} \text { de } \\
\text { oPO4eração; } 10 \text { min de } \\
\text { agitação manual; } \\
\text { 1-6 h de sedimentação }\end{array}$ & ${ }^{*} 91 \% \mathrm{PO}_{4}^{3-}$ & $\begin{array}{l}\text { Etter } \text { et al. } \\
\quad(2011)\end{array}$ \\
\hline $\begin{array}{r}\text { Esgoto munic } \\
\text { após digestã } \\
\text { anaeróbia } \\
(100 \mathrm{mg} / \mathrm{l} \mathrm{PO} \\
\end{array}$ & & $\begin{array}{l}\mathrm{Mg}(\mathrm{OH})_{2} \\
\text { e } \mathrm{NaOH}\end{array}$ & $1,0 / 1,3 / 1,0$ & $8,5 \pm 0,3$ & $\begin{array}{l}\text { Reator de leito fluidizado; } \\
150 \text { e } 500 \mathrm{~m}^{3} / \text { dia, } \mathrm{TDH} \approx 10 \\
\text { dias }\end{array}$ & ${ }^{*} 90 \% \mathrm{PO}_{4}^{3-}$ & $\begin{array}{l}\text { Ueno e } \\
\text { Fujii } \\
(2001)\end{array}$ \\
\hline $\begin{array}{l}\text { Esgoto munic } \\
\text { após digestã } \\
\text { anaeróbia } \\
(105 \text { a } 210 \mathrm{~m} \\
\left.\mathrm{PO}_{4}{ }^{3-}\right) \\
\end{array}$ & & $\begin{array}{l}\mathrm{MgO} \\
\text { industrial } \\
\text { hidratado }\end{array}$ & $2,1 / 32 / 1,0$ & 8,1 a 8,6 & $\begin{array}{l}\text { Reator de leito fluidizado de } \\
2 \text { estágios (125 e } 3.260 \mathrm{~L})\end{array}$ & $* 77 \% \mathrm{PO}_{4}^{3-}$ & $\begin{array}{l}\text { Crutchik et } \\
\text { al. (2017) }\end{array}$ \\
\hline $\begin{array}{r}\text { Efluente de Ut } \\
\text { de esterco avi } \\
(1.318 \mathrm{mg} / \mathrm{l} \mathrm{N}\end{array}$ & $\begin{array}{l}\text { ASB } \\
\text { iário } \\
\mathrm{JH}_{4}^{+} \text {) }\end{array}$ & $\begin{array}{c}\mathrm{MgCl}_{2} \cdot 6 \mathrm{H}_{2} \mathrm{O} \\
\mathrm{e} \mathrm{KH}_{2} \mathrm{PO}_{4}\end{array}$ & $1,0 / 1,0 / 1,0$ & 9,0 & $\begin{array}{l}\text { Frascos de vidro, } 15 \mathrm{~min} \\
\text { agitação magnética, } 30 \mathrm{~min} \\
\text { de sedimentação }\end{array}$ & $85 \% \mathrm{NH}_{4}^{+}$ & $\begin{array}{l}\text { Yetilmezso } \\
\text { y e Sapci- } \\
\text { Zengin } \\
(2009)\end{array}$ \\
\hline $\begin{array}{l}\text { Lodo de esgotc } \\
\text { municipal }(749 \\
\left.\mathrm{mg} / 1 \mathrm{NH}_{4}^{+}\right) \\
\end{array}$ & & $\begin{array}{l}\mathrm{MgCl}_{2} .6 \mathrm{H}_{2} \mathrm{O} \text { e } \\
85 \% \mathrm{H}_{3} \mathrm{PO}_{4}\end{array}$ & $1,5 / 1,0 / 1,0$ & 9 & $\begin{array}{c}\text { Frascos de vidro (batelada), } \\
\text { 30min/250 rpm, } 1 \mathrm{~h} \text { de } \\
\text { sedimentação }\end{array}$ & $89 \% \mathrm{NH}_{4}^{+}$ & $\begin{array}{l}\text { Uysal et al. } \\
\text { (2010) }\end{array}$ \\
\hline $\begin{array}{c}\text { Pecuária } \\
(225-519 \\
\left.\mathrm{mg} / 1 \mathrm{NH}_{4}^{+}\right) \\
\end{array}$ & $\mathrm{Na}_{2} \mathrm{HI}$ & $\begin{array}{l}\mathrm{HPO}_{4}, \mathrm{Mg}(\mathrm{OH})_{2} \mathrm{e} \\
\mathrm{MgCl}_{2} 6 \mathrm{H}_{2} \mathrm{O}\end{array}$ & $1,3 / 1,0 / 1,0$ & 8,5 & $\begin{array}{l}\text { Reator (batelada) com } \\
\text { agitação magnética }\end{array}$ & $90 \% \mathrm{NH}_{4}{ }^{+}$ & $\begin{array}{l}\text { Uludag- } \\
\text { Demier } \text { et } \\
\text { al. }(2005) \\
\end{array}$ \\
\hline $\begin{array}{l}\text { Industrial } \\
(280 \mathrm{mg} / \mathrm{l} \\
\left.{\text { de } \mathrm{NH}_{4}^{+}}^{+}\right) \\
\end{array}$ & $\begin{array}{r}\mathrm{Mg} \\
\text { hidri } \\
\text { partir }\end{array}$ & $\begin{array}{l}\mathrm{g}(\mathrm{OH})_{2} \\
\text { ratado a } \\
\mathrm{r} \text { do } \mathrm{MgO} \\
\end{array}$ & $1,5 / 1,0 / 1,25$ & 8,5 & $\begin{array}{c}\text { Reator cônico semicontínuo } \\
\text { com agitação de } 80 \mathrm{rpm} . \\
\text { Reator fluidizado }\end{array}$ & $\begin{array}{l}73 \% \mathrm{NH}_{4}^{+} \\
82 \% \mathrm{NH}_{4}^{+}\end{array}$ & $\begin{array}{l}\text { Castro } \\
(2014)\end{array}$ \\
\hline $\begin{array}{c}\text { Industrial } \\
(2.652 \mathrm{mg} / \mathrm{l} \\
\left.\mathrm{NH}_{4}^{+}\right) \\
\end{array}$ & & $\begin{array}{l}\text { ittern e } \\
\mathrm{H}_{2} \mathrm{PO}_{4}\end{array}$ & $1,6 / 0,6 / 1,0$ & 9,6 & $\begin{array}{l}\text { Jar Test (Batelada); } 10 \text { min } \\
\text { agitação, } 10 \text { min de } \\
\text { sedimentação; }\end{array}$ & $36 \% \mathrm{NH}_{4}^{+}$ & $\begin{array}{l}\text { Diwani et } \\
\text { al. }(2007)\end{array}$ \\
\hline \multicolumn{3}{|c|}{$\begin{array}{c}\text { Industrial } \\
\left(2.320 \mathrm{mg} / 1 \mathrm{NH}_{4}^{+}\right)\end{array}$} & $1,0 / 1,0 / 1,0$ & 8,5 a 9,0 & $\begin{array}{l}\text { Frascos de vidro (batelada), } \\
200 \mathrm{rpm}, 6 \text { h de sedimentação }\end{array}$ & $\begin{array}{l}78 \% \mathrm{NH}_{4}^{+} \\
99 \% \mathrm{PO}_{4}{ }^{3-}\end{array}$ & $\begin{array}{c}\text { Chime } \\
\text { nos } e t \\
\text { al. } \\
(2003) \\
\end{array}$ \\
\hline
\end{tabular}

* a formação de estruvita foi indicada considerando a alta remoção de amônia, nos casos com condições ajustadas para recuperação do $P$. 

precipitação de estruvita. Brazilian Journal of Production Engineering, 6(9), Edição Especial "Iniciação Científica", $20-36$.

Além dos 10 trabalhos selecionados (Tabela 10), com a busca dos mais citados, outros trabalhos relevantes envolvendo efluentes similares e com outras ponderações sobre a viabilidade do processo são destacados na continuação do texto.

Uma análise bibliométrica foi realizada por Suela et al. (2018), a qual identificou os 20 artigos mais relevantes sobre o tratamento de águas residuais envolvendo a precipitação de estruvita. Muitos dos artigos examinados acima coincidem com a lista de Suela et al. (2018), mas sua revisão objetivou a avaliação da relevância do tema, sem examinar os detalhes e a efetividade do processo, como feito nesta revisão. A atualidade e a importância da técnica como uma alternativa ambientalmente eficaz, e com potencial aplicação em larga escala foram destacados pelos autores. Morita et al. (2019) apresentaram uma detalhada revisão da literatura focada no processo de nucleação e nos prováveis mecanismos da precipitação da estruvita.

Moreira (2009) foi um dos pioneiros nos estudos brasileiros com foco na busca de fontes alternativas de reagentes para reduzir os custos da precipitação da estruvita. $\mathrm{O}$ autor avaliou a viabilidade operacional do emprego de resíduos (lixiviados de aterros sanitários, borra de fosfato, oriunda do tratamento de superfícies metálicas, e brucita escura, gerada pela decomposição térmica da magnesita $\left.\left(\mathrm{MgCO}_{3}\right)\right)$, como fontes de íons fosfato e magnésio, para a produção de estruvita. Ensaios realizados em Jar Test, com agitação de 100 rpm, em pH de 8,5 e razão equimolar dos constituintes (utilização de resíduos, como reagentes alternativos) permitiram uma recuperação de $76 \%$ da $\mathrm{NH}_{3}$.

Celen e Türker (2001), em escala laboratorial, foram capazes de recuperar 60 a $70 \%$ da amônia de um efluente industrial, após digestão anaeróbia, $\left(\mathrm{NH}_{3}\right.$ e $\mathrm{K}^{+}=1.400$ e $2.150 \mathrm{mg} / \mathrm{L}$ ) com adição de $\mathrm{MgO}$ (85\% de pureza) e $\mathrm{H}_{3} \mathrm{PO}_{4}$ (75\%, P.A.) para obter $\mathrm{Mg}^{2+} / \mathrm{NH}_{4}+/ \mathrm{PO}_{4}{ }^{3-} \approx 1,2 / 1,0 / 1,2 \mathrm{em}$ $\mathrm{pH} 8,5$ a 9,0 . A recuperação ultrapassa $90 \%$ com $\mathrm{MgCl}_{2} .6 \mathrm{H}_{2} \mathrm{O}$ e é independente da temperatura entre 25 e $40^{\circ} \mathrm{C}$. Os autores demonstraram que proporções acima de $20 \%$ de excesso de $\mathrm{PO}_{4}{ }^{3-}$ ou $\mathrm{Mg}^{2+}$ (a partir de $\mathrm{MgCl}_{2} .6 \mathrm{H}_{2} \mathrm{O}$ ou $40 \%$ de $\mathrm{MgO}$ ) não melhoram a remoção do $\mathrm{NH}_{4}{ }^{+}$. $\mathrm{A}$ estruvita produzida foi purificada por dissolução ácida, seguida de recristalização em $\mathrm{pH}$ alcalino, com $86 \%$ de eficiência. A viabilidade financeira do processo independeu da fonte de $\mathrm{Mg}^{2+}$.

Celen et al. (2007) modelaram a precipitação da estruvita a partir de efluente de suinocultura $\left(\mathrm{Mg}^{2+} / \mathrm{NH}_{4}+/ \mathrm{K}^{+} / \mathrm{PO}_{4}{ }^{3-} \approx 0,6 / 14 / 3,3 / 1,0 ; \mathrm{NH}_{3}, \mathrm{Ca}^{2+}\right.$ e $\mathrm{HCO}_{3}{ }^{-} \approx 1.410,98$ e $\left.900 \mathrm{mg} / \mathrm{L}\right)$ com o software Visual Minteq mediante a adição de base $(\mathrm{NaOH}$; condição $\mathrm{C} 1)$ e base mais $\mathrm{MgCl}_{2} .6 \mathrm{H}_{2} \mathrm{O}$ para alcançar $\mathrm{Mg}^{2+} / \mathrm{PO}_{4}{ }^{3-}$ iguais a 1,0 (C2), $1,5(\mathrm{C} 3)$ e 2,0 (C4), em pH 8,5. O modelo estimou uma recuperação de $62 \%$ com $\mathrm{C} 1$, e de 93 a $99,5 \%$ do $\mathrm{PO}_{4}{ }^{3-}$ para $\mathrm{C} 2$ a $\mathrm{C} 4$, unicamente na forma de estruvita. Nos ensaios de precipitação realizados com o efluente, a condição $\mathrm{C} 1$ promoveu $55 \%$ de remoção do $\mathrm{PO}_{4}{ }^{3-}$ e as demais condições de 94 a $99 \%$ na forma de estruvita e fosfatos de cálcio. A condição equimolar (C2) foi sugerida como a mais atrativa para o processo. Apesar do efluente conter alto teor de K, tanto o modelo, quanto os ensaios químicos, não indicaram a formação da estruvita potássica. Isso deve ter ocorrido devido à alta razão $\mathrm{NH}_{4}+/ \mathrm{K}^{+} \approx 4$.

O lixiviado bruto do Aterro Controlado Jockey Club de Brasília foi empregado por Diniz (2010) como fonte de amônia para precipitação de estruvita, em Jar Test, sob agitação de $200 \mathrm{rpm}$, em pH 9,0 e com a adição de reagentes (grau analítico) para alcançar $\mathrm{Mg}^{+2} / \mathrm{NH}_{4}{ }^{+} / \mathrm{PO}_{4}{ }^{-3}$ de 

precipitação de estruvita. Brazilian Journal of Production Engineering, 6(9), Edição Especial "Iniciação Científica", $20-36$.

1,5/1,0/1,0. Nestas condições 85,5\% da amônia foi recuperada. Tengrui (2007), também trabalhando com o lixiviado de aterro sanitário (da cidade de Chongqing, China), em condições idênticas de pH e agitação, mas com razão equimolar, alcançou 97,5\% de remoção de amônia. Já Schilling (2008), também em condições idênticas, teve de adicionar um excesso de reagentes P.A. $\left(\mathrm{Mg}(\mathrm{OH})_{2}\right.$ e $\mathrm{H}_{3} \mathrm{PO}_{4}$ para obter $\mathrm{Mg}^{+2} / \mathrm{NH}_{4}+\mathrm{PO}_{4}{ }^{-3} \approx 2,0 / 1,0 / 1,75 ; \mathrm{NH}_{4}{ }^{+}=1.080 \mathrm{mg} / \mathrm{L}$; após eliminação de parte da alcalinidade carbonácea por volatilização do gás carbônico em $\mathrm{pH}$ 4,0) para alcançar $90 \%$ de remoção de amônia ao tratar o chorume altamente recalcitrante do aterro sanitário de Gramacho-RJ. Nos três estudos a concentração residual de amônia foi suficientemente reduzida ( $<200 \mathrm{mg} / \mathrm{L}$ ) para permitir o tratamento biológico do efluente (Uysal et al., 2010). As elevadas recuperações alcançadas estão provavelmente associadas ao uso de reagentes P.A., ao emprego eficientes sistemas de mistura (Jar Test) e de altas doses de $\mathrm{Mg}^{2+}$. Infelizmente os 3 efluentes não foram completamente caracterizados no que se refere a presença de interferentes como $\mathrm{K}^{+}$e $\mathrm{Ca}^{2+}$, nem o tamanho dos grãos obtidos foi informado.

Kabdasli et al. (2009) avaliaram a precipitação de estruvita sob duas situações, uma partir de efluentes brutos de abatedouros e como etapa de refino pós-tratamento biológico do mesmo efluente. Verificaram que a precipitação da estruvita sob condições equimolares de reagentes $\left(\mathrm{MgCl}_{2} .6 \mathrm{H}_{2} \mathrm{O}\right.$ e $\left.\mathrm{NaH}_{2} \mathrm{PO}_{4} .2 \mathrm{H}_{2} \mathrm{O}\right)$, com $\mathrm{pH}$ entre 9,0 e 9,5 reduz a concentração residual de amônia para valores na faixa de 22 a $30 \mathrm{mg} / \mathrm{l}$ (recuperação de 80 a 90\%), independente das concentrações iniciais $\left(\mathrm{NH}_{4}{ }^{+}\right.$de 155 a $\left.220 \mathrm{mg} / \mathrm{L}, \mathrm{NH}_{4}+\mathrm{PO}_{4}{ }^{3-} \approx 122, \mathrm{Ca}^{2+} \approx 60 \mathrm{mg} / \mathrm{L}\right)$ e deve ser implementada antes do tratamento biológico.

Com soluções preparadas a partir de reagentes P.A., Castro (2014) demonstrou que a adição de $\mathrm{PO}_{4}{ }^{3-}$, para obter razões de $\mathrm{PO}_{4}{ }^{3-}-\mathrm{NH}_{4}{ }^{+}$de 1,25 a 1,5 , é mais efetivo para aumentar a remoção de amônia $(\approx 98 \%)$, do que com o emprego de proporções similares de $\mathrm{Mg}^{2+}(\approx 90 \%)$. As sínteses com excesso estequiométrico de $\mathrm{PO}_{4}{ }^{3-}$ permitiram o enquadramento do teor residual de nitrogênio amoniacal do efluente sintético ao padrão de lançamento CONAMA 430/2011 (BRASIL, 2011), com apenas 4 min de tempo de reação em Jar-test, e revelaram a alta velocidade de sedimentação zonal $(\geq 0,6 \mathrm{~m} / \mathrm{s})$ e ótimo adensamento da estruvita produzida (índice volumétrico do lodo - IVL $<50$ ).

Castro (2014) também avaliou a precipitação de estruvita em reator cônico (1,8 litro, TDH = $51 \mathrm{~min}$ ) com agitação mecânica, e em reator de leito fluidizado (1,4 L, com decantador de 31,7 L e TDH de 1,5 e 97 min, respectivamente) com suspensões de magnésia industrial ( $80 \%$ de $\mathrm{MgO}$ ) hidratada para alcançar razão molar $\mathrm{Mg}^{2+} / \mathrm{NH}_{4}{ }^{+} / \mathrm{PO}_{4}{ }^{3-} \approx 1,5 / 1,0 / 1,8 ;$ em pH de 8,2 $\pm 0,1$. $\mathrm{O}$ reator cônico, operado de forma semicontínua por 8 horas/dia, foi capaz de recuperar $73 \%$ da amônia presente no efluente $\left(\mathrm{NH}_{4}{ }^{+}=280 \mathrm{mg} / \mathrm{l}\right)$. O reator de leito fluidizado alcançou $82 \%$ de remoção e gerou cristais maiores $(71 \%>0,5 \mathrm{~mm})$, uma vez que não promove a quebra dos cristais, como no reator agitado. $\mathrm{O}$ estudo também avaliou o uso da farinha de osso $(23 \% \mathrm{P})$, solubilizada em $\mathrm{H}_{2} \mathrm{SO}_{4}$, foi como fonte de $\mathrm{P}$ de baixo custo.

Zhou et al. (2016) avaliaram como altamente satisfatória a eficiência de recuperação do fósforo presente em efluente gerado pelo tratamento secundário, via precipitação da estruvita, em reatores de cristalização (Struvia ${ }^{\mathrm{TM}}$, Ostrara's Pearl ${ }^{\circledR}$ e AirPrex ${ }^{\circledR}$ ) mediante adição de $\mathrm{MgCl}_{2}$, e controle do $\mathrm{pH}$ (8-9) com $\mathrm{NaOH}$. Outros reatores também de escala industrial (NuReSys ${ }^{\circledR}$,

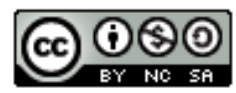



precipitação de estruvita. Brazilian Journal of Production Engineering, 6(9), Edição Especial "Iniciação Científica", 20-36.

Unitika Phosnix ${ }^{\circledR}$ e Phospaq ${ }^{\mathrm{TM}}$ ) são operados com especial ênfase na recuperação do $\mathrm{PO}_{4}{ }^{3-}$ em efluentes com pelo ao menos $50 \mathrm{mg} / \mathrm{L}$ de $\mathrm{PO}_{4}{ }^{3-}$ e alta relação N/P> 1,0. Sob tais condições, grãos maiores que $0,5 \mathrm{~mm}$ são produzidos, taxa de recuperação de $\mathrm{P}$ maiores que $70 \%$ são alcançadas, e o processo se torna economicamente viável mediante o emprego da magnésia de grau industrial, como reagentes de baixo custo, e que dispensa suplementação de base (Desmidt et al., 2013; Remy et al., 2013).

Crutchik et al. (2017) reportarama recuperação média de $77 \%$ do $\mathrm{PO}_{4}{ }^{3-}$ presente em efluente municipal, após tratamento anaeróbio, na forma de “pellets' $(61 \%>0,5 \mathrm{~mm})$ com um grande reator de leito fluidizado de 2 estágios (um de 125 litros para mistura/precipitação e outro de 3.260 litros de sedimentação, TDH de $\approx 2$ e $100 \mathrm{~min}$, respectivamente). Adicionou-se apenas pasta de magnésia hidratada (Equação 4), como fonte de $\mathrm{Mg}^{2+}$ e de base, uma vez que o efluente já contém $\mathrm{NH}_{4}{ }^{+}$suficiente $\left(\mathrm{Mg}^{2+} / \mathrm{NH}_{4}+\mathrm{PO}_{4}{ }^{3-} \approx 0,5 / 32 / 1,0 ; \mathrm{NH}_{4}{ }^{+} \approx 1.260 \mathrm{mg} / \mathrm{l}, \mathrm{Ca}^{2+}\right.$ e K ${ }^{+} \approx 80$ $\mathrm{mg} / \mathrm{l})$ para formação da estruvita. Os autores notaram uma significativa redução da concentração de amônio no efluente após o tratamento, a qual supera o esperado ao considerar à sua remoção pela precipitação da estruvita, e atribuíram o efeito à perdas de amônia livre por volatilização no reator, o qual não possui sistema de recirculação do ar usado na fluidização. Além disso, Crutchik et al. (2017) destacaram que a alta razão molar $\left(\mathrm{NH}_{4}{ }^{+} / \mathrm{Ca}^{2+} \approx 32\right)$, e alcalinidade $\left(3.900 \mathrm{mg} /{\mathrm{L} \mathrm{HCO}_{3}}^{-}\right)$do efluente diminuem a interferência do $\mathrm{Ca}^{2+}$ sobre a formação da estruvita ou da hidroxiapatita (fosfato de cálcio), uma vez que a precipitação carbonatos $\left(\mathrm{MgCO}_{3(\mathrm{~s})}\right.$ e $\left.\mathrm{CaCO}_{3(\mathrm{~s})}\right)$ é favorecida sob estas condições. A presença destes, conjuntamente com estruvita e fosfato de magnésio (catita) foi confirmada por DRX. A retenção de parte do $\mathrm{Mg}^{2+}$ pelo $\mathrm{MgCO}_{3(\mathrm{~s})}$ foi apontada como o maior obstáculo à obtenção de maiores rendimentos na recuperação do $\mathrm{P}$ como estruvita. Mesmo assim, o tratamento com magnésia industrial apresenta custo $(\approx 50 \%)$ inferior, frente a remoção do $\mathrm{P}$ mediante sua precipitação com sais de $\mathrm{Fe}$ e Al, e saldo financeiro positivo após a comercialização do fertilizante.

Santos (2011) avaliou a remoção de N e P presente em três efluentes agroindustriais (de suinocultura, descarte de refrigerante e sangue bovino). A adição de $\mathrm{MgCl}_{2} .6 \mathrm{H}_{2} \mathrm{O}$ para alcançar uma proporção equimolar permitiu a recuperar de mais de $95 \%$ dos nutrientes. Os ensaios foram realizados em pH 9,5 apresentou as maiores remoções do que em $\mathrm{pH}$ 9,0. A análise por DRX revelou a precipitação de estruvita apenas no tratamento dos efluentes de suinocultura e do descarte de refrigerante, já no tratamento do sangue bovino houve apenas a formação de compostos amorfos.

Guest et al. (2009) destacam que o emprego de novas tecnologias de recuperação sustentável de recursos, estabelece um novo paradigma, o qual retira o foco daquilo que deve ser removido do efluente, e foca naquilo que pode ser recuperado. Nesse sentido, a recuperação de nutrientes via precipitação de estruvita se apresenta como uma alternativa que pode ser explorada com ganhos financeiros, agrícolas e ambientais.

\section{CONSIDERAÇÕES FINAIS}

Este trabalho apresentou uma ampla revisão na literatura sobre recuperação de nutrientes de efluentes diversos via precipitação da estruvita. A maioria dos estudos destaca que o controle do pH é crítico para maximizar a eficiência de remoção, exercendo também uma forte influência

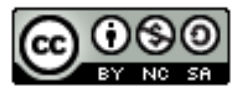



precipitação de estruvita. Brazilian Journal of Production Engineering, 6(9), Edição Especial "Iniciação Científica", 20-36.

sobre a pureza da estruvita obtida. $\mathrm{O}$ ajuste das condições ótimas para o tratamento de efluentes deve considerar às grandes variações composicionais destacadas nesta revisão, assim não se espera definir uma única condição igualmente adequada para recuperação de nutrientes, via precipitação da estruvita.

No geral, os melhores resultados foram obtidos em pH entre 8,5 e 9,0, com adição de reagentes puros, seguidos do uso fontes alternativas de nutrientes, de baixo custo, para alcançar uma razão equimolar entre os constituintes. Muitos casos, objetivaram ajustar a adição de um pequeno excesso estequiométrico de $\mathrm{Mg}^{2+}$ para aumentar a eficiência da precipitação. A magnésia de grau industrial é o reagente de baixo custo mais utilizado nos estudos que avaliaram a viabilidade econômica do processo.

Na maior parte dos estudos a remoção de $\mathrm{N}$ foi inferior à recuperação do $\mathrm{P}$, dada a formação de outras fases, como os fosfatos de cálcio e carbonato de magnésio. Além disso, diversos trabalhos reforçam que a presença de $\mathrm{K}^{+}$no efluente deve ser considerada (uma vez que este compete como $\mathrm{NH}_{4}{ }^{+}$durante a formação da estruvita) ao se ajustar as quantidades de reagentes adicionados, e ao avaliar a efetividade do processo de tratamento. Destaca-se que a transferência das condições laboratoriais, com efluentes sintéticos, raramente se adequam aos de efluentes reais, os quais demandam ajustes específicos nas condições de tratamento.

A viabilidade financeira da inclusão da etapa de precipitação da estruvita ao processo de tratamento de efluentes reais, realizado em estações complexas, é de difícil avaliação. Pois além dos insumos, demanda de pessoal, energia e capital investido, sua inclusão torna a operação da estação ainda mais complicada. Contudo, a operação também pode se beneficiar dado o menor risco de entupimento de tubulações, redução nos períodos parados para manutenção e substituição de peças obstruídas por incrustações, e da comercialização da estruvita como fertilizante de liberação lenta. Uma característica própria da estruvita, independentemente do efluente tratado, e que é muito destacada nos estudos que envolveram a aplicação agronômica.

As altas taxas de recuperação de $\mathrm{N}$ e P reportadas nos estudos revisados reforçam que produção de estruvita é uma alternativa viável para a produção de fertilizante mediante a reciclagem de nutrientes. A tecnologia já está disponível comercialmente (sistemas Struvia ${ }^{\mathrm{TM}}$, Ostara's Pearl ${ }^{\circledR}$, AirPrex ${ }^{\circledR}, \mathrm{NuReSys}^{\circledR}$, Unitika Phosnix ${ }^{\circledR}$ e Phospaq ${ }^{\mathrm{TM}}$ ), porém cada efluente requer ajustes particulares para otimizar o tratamento. A sua inclusão da etapa de precipitação da estruvita dentre as operações de plantas de grande escala se mostra promissora, e pode prover ganhos financeiros mediante a comercialização do produto, além de reduzir os custos globais de operação e manutenção das estações.

\section{AgRADECIMENTOS}

Projeto Financiado pelo Edital FAPES Nº 01/2015 - Cooperação FAPES/VALE/FAPERJ.

\section{REFERÊNCIAS BIBLIOGRÁFICAS}

Battistoni, P., Boccadoro, R., Fatone, F., \& Pavan, P. (2005). Auto - nucleation and crystal growth of struvite in a demonstrative fluidized bed reactor (FBR). Environmental Technology, 26(9), 975-982.

Bouropoulos, N. C., \& Koutsoukos, P. G. (2000). Spontaneous Precipitation of struvite from aqueous solutions. Journal of Crystal Growth, 213(3), 381-388. 

precipitação de estruvita. Brazilian Journal of Production Engineering, 6(9), Edição Especial "Iniciação Científica", $20-36$.

Ministério do Meio Ambiente. (2011). Resolução $n^{o}$. 430/2011. Recuperado de http://www2.mma.gov.br/port/conama/legiabre.cfm?codlegi=646.

Bhuiyan, M. I. H., Mavinic, D. S., \& Koch, F. A. (2008). Phosphorus recovery from wastewater through struvite formation in fluidized bed reactors: a sustainable approach. Water Science Technology, 57(2), 175-181.

Camargo, C. C. (2012). Tratamento de lixiviado de aterro sanitário: Remoção de amônia por formação de estruvita. (Dissertação de Mestrado). Universidade Estadual de Campinas, Campinas, São Paulo, Brasil.

Castro, S.R. (2014). Precipitação de estruvita: recuperação de nitrogênio e fósforo utilizando fontes alternativas de reagentes (Tese de doutorado). Universidade Federal de Minas Gerais, Belo Horizonte, Minas Gerais, Brasil.

Celen, I., Buchanan, J. R., Burns, R. T., Robinson, R. B., \& Raman, D. R. (2007). Using a chemical equilibrium model to predict amendments required to precipitate phosphorus as struvite in liquid swine manure. Water Research, 41(8), 1689-1696.

Celen, I., \& Türker, M. (2001). Recovery of ammonia as struvite from anaerobic digester effluents. Environ. Technol, 22(11), 1263-1272.

Cerna, C. E. L. (2008). Degradação da Amônia em Efluentes com Ácido de Caro (Dissertação de Mestrado). Pontifícia Universidade Católica de Rio de Janeiro, Rio de Janeiro, RJ, Brasil.

Chimenos, J. M., Fernandez, A. I., Villalba, G., Segarra, M., Urruticoechea, A., Artaza, B., \& Espiell, F. (2003). Removal of ammonium and Phosphates from wastewater resulting from the Process of cochineal extraction using $\mathrm{MgO}$ containing by-Product. Water Research, 37(7), 1601-1607.

Crutchik, D., Morales, N., Vázquez-Padín, J. R., \& Garrido, J. M. (2017). Enhancement of struvite pellets crystallization in a full-scale plant using an industrial grade magnesium product. Water Sci Technol, 75(3), 609-618.

Darwish, M., Aris, A., Puteh, M.H., Abideen, M.Z, \& Othman, M. N. (2016). AmmoniumNitrogen Recovery from Wastewater by Struvite Crystallization Technology. Separation \& Purification Reviews, 45, 261-274.

Desmidt, E., Ghyselbrecht, K., Monballiu, A., Rabaey, K., Verstraete, W., \& Meesschaert, B. D. (2013). Factors influencing urease driven struvite precipitation. Separation and Purification Technology, 110, 150-157.

Diniz, D. T. L. (2010). Remoção de Nitrogênio Amoniacal de Lixiviado de Aterro de Resíduos Sólidos Por Precipitação Química com Formação de Estruvita (Dissertação de Mestrado). Universidade de Brasília, Brasília, Distrito Federal, Brasil.

Doyle, J. D., Oldring, K., Churchley, J., Price, C., Parsons, S. A. (2003). Chemical control of struvite Precipitation. Journal of Environmental Engineering, 129(5), 419-426.

Diwani, G. el, Rafie, S. H. el, Ibiari, N. N. el, \& Aila, H. I. el (2007). Recovery of ammonia nitrogen from industrial wastewater treatment as struvite slow releasing fertilizer. Desalination, 214(1-3), 200-214.

Etter, B., Tilley, E., Khadka, R., \& Udert, K. M. (2011). Low-cost struvite Production using source-separated urine in Nepal. Water Research, 45(2), 852-862.

Forrest, A. L., Fattah, K. P., Mavinic, D. S., \& Koch, F. A. (2008). Optimizing struvite production for phosphate recovery in WWTP. Journal of Environmental Engineering, 134(5), 395-402.

Giordano, G., Ferreira, J.A., Pires, J.C.A., Ritter, E., Campos, J.C., \& Rosso, T.C. de A. (2002, outubro). Tratamento do Chorume do Aterro Metropolitano de Gramacho - Rio de Janeiro - 

precipitação de estruvita. Brazilian Journal of Production Engineering, 6(9), Edição Especial "Iniciação Científica", $20-36$.

RJ. Anais do Congresso Interamericano de Ingenharia Sanitaria Y Ambiental, Cancún, Quintana Roo, México, 28.

Guest, J. S., Skerlos, S. J., Barnard, J. L., Beck, M. B., Daigger, G. T., Hilger, H., Jackson, S. J., Karvazi, K., Kelly, L., Macpherson, L., Mihelcic, J. R., PRAMANIK, A., Raskin, L., Loosdrecht, M. C. M. van, Yeh, D., \& Love, N. G. (2009). A New Planning and Design Paradigm to Achieve Sustainable Resource Recovery from Wastewater. Environmental Science and Technology, 43(16), 6126-6130.

Halling-Sorensen, B., \& Jorgensen, S.E. (1993). The Removal of Nitrogen Compounds from Wastewater. Elsevier Science Publishers. Amsterdam, Netherlands, 443PP.

Hostert, J., Kamlet, O., SU, Z., Kane, N., \& Renner, J.N. (2020). Exploring the effect of a Peptide additive on struvite formation and morphology: a high-throughput method. RSC Advances, 10, 39328-39337.

Iaconi, C., Pagano, M., Ramadori, R., \& Lopez, A. (2010). Nitrogen recovery from stabilized municipal landfill leachate. Bioresource and technology, 101(6), 1732-1736.

Jaffer, Y., Clark, T. A, \& Pearce, P. (2002). Potential phosphorus recovery by struvite formation. Water Research, 36(7), 1834-1842.

Kabdasli, I., Tünay, O., \& Özcan, P. (2009). Application of struvite precipitation coupled with biological treatment to slaughterhouse wastewaters. Environmental Technology, 30 (10), 10951101.

Kim, D., Min, K.J., Lee, K., Yu, M.S., \& Park, K.Y. (2017). Effects of pH, molar ratios and pre-treatment on phosphorus recovery through struvite crystallization from effluent of anaerobically digested swine wastewater. Environmental Engineering Research, 22(1), 12-18.

Ledesma, L. M. S. (2014). Produção de estruvita a Partir de esgoto doméstico (Dissertação de Mestrado). Escola Politécnica da Universidade de São Paulo, São Paulo, SP, Brasil.

Lei, X., Shimada, S., Intabon, K., \& Maekawa, T. (2006). Pretreatment of methane fermentation effluent by physico-chemical Processes before applied to soil trench system. Agric. Eng. Int.: CIGR E J., 8, 1-15.

Liu, Y. H., Rahman, M., M., \& Kwag, J. H. (2011). Eco-friendly production of maize using struvite recovered from swine wastewater as a sustainable fertilizer source. Asian-Australasian Journal of Animal Sciences, 24(12), 1699-1705.

Moreira, F. A. (2009). Remoção de amônia em lixiviado de aterro sanitário como estruvita (Dissertação de Mestrado). Universidade Federal de Minas Gerais, Belo Horizonte, Minas Gerais, Brasil.

Nelson, N.O, Mikkelsen, R.L., \& Hesterberg, D.L. (2003). Struvite Precipitation in anaerobic swine lagoon liquid: effect of $\mathrm{PH}$ and $\mathrm{Mg}$ : $\mathrm{P}$ ratio and determination of rate constant. Bioresour Technol, 89(3), 229-236.

Memelli, M.S, Roque, R.P., Bená, N.B., Filho, \& Gonçalves, R.F. (2018). Recuperação de Nutrientes via precipitação de estruvita para uso agrícola - Uma revisão. Anais do Workshop Internacional de Biorremediação de Áreas Contaminadas, Vitória, ES, Brasil, 2.

Morita, D.M., Avila, R.L. \& Aidar, F.N. (2019). Nucleação na formação de estruvita: estado da arte. Eng. Sanit. Ambient, 24(4), 637-654.

Munch, E.V., \& Barr, K. (2001). Controlled struvite crystallisation for removing phosphorus from anaerobic digester side streams. Water Res., 35(1), 151-159.

Organização das Nações Unidas. (2015). A Agenda 2030 para o Desenvolvimento Sustentável. Recuperado de http://www.agenda2030.org.br/sobre/. 

precipitação de estruvita. Brazilian Journal of Production Engineering, 6(9), Edição Especial "Iniciação Científica", $20-36$.

Pereira, L.P.F., \& Mercante, C.T.J. (2005). A amônia nos sistemas de criação de Peixes e seus efeitos sobre a qualidade da água: Uma revisão. B. Inst. Pesca, 31(1), 81-88.

Rahman, M. M., Salleh, M. A. M., Rashid, U., Ahsan, A., Hossain, M. M., \& RA, C. S. (2014). Production of slow release crystal fertilizer from wastewaters through struvite crystallization A review. Arabian Journal of Chemistry, 7(1), 139-155.

Remy, M., Driessen, W., Hendrickx, T., \& Haarhuis, R. (2013). Recovery of phosphorus by formation of struvite with the phospaq ${ }^{\mathrm{TM}}$ process. Proceedings of the European Biosolids and Organic Resources Conference. Manchester, England, United Kingdom, 18.

Santos, W. R. B. (2011). Remoção de nitrogênio e fósforo Presentes em efluentes agroindustriais Pela Precipitação de estruvita (Dissertação de Mestrado). Universidade Federal de Santa Maria, Santa Maria, Rio Grande Sul, Brasil.

Schilling, P. F. (2008). Precipitação de nitrogênio amoniacal na forma de estruvita em lixiviado de aterro sanitário (Dissertação de Mestrado). Universidade Federal do Rio de Janeiro, Rio de Janeiro, RJ, Brasil.

Sikosana, M.K.L.N., Randall, D.G., \& Blottnitz, H. von. (2017). A technological and economic exploration of phosphate recovery from centralized sewage treatment in a transitioning economy context. Water SA, 43(2), 343-353.

Suela, S. C., Porto, P. S. S., \& Freitas, R. R. (2018). Tratamento de águas residuais para produção de estruvita: Um estudo bibliométrico. Research, Society and Development, 7(9), 1179380.

Talboys, P.J., Heppell, J., Roose, T., Healey, J.R., Jones, D.L., \& Withers, P. J. A. (2016) Struvite: a slow-release fertilizer for sustainable phosphorus management. Plant and Soil, 401, 109-123.

Tengrui, L. (2007). Comparison between biological treatment and chemical Precipitation for nitrogen removal from old landfill leachate. American Journal of Environmental Sciences, 3(4), 83-187.

Ueno, Y., \& Fujii, M. (2001). Three years' experience of operating and selling recovered struvite from full-scale Plant. Environmental Technology, vol. 22, 1373-1381.

Uludag-Demirer, S., Demirer, G. N., \& Chen, S. (2005). Ammonia removal from anaerobically digested dairy manure by struvite Precipitation. Process Biochemistry, 40(12), 3667-3674.

Uysal, A., Yilmazel, Y. D., \& Demirer, G. N. (2010). The determination of fertilizer quality of the formed struvite from effluent of a sewage sludge anaerobic digester. Journal of Hazardous Materials, 181(1-3), 248-254.

Wilsenach, J. A., Schuurbiers, C. A. H., \& Loosdrecht, M. C. M. van (2007) Phosphate and Potassium recovery from source separated urine through struvite Precipitation. Water Research, 41(2), 458-466.

Yan H, \& Shih K. (2016). Effects of calcium and ferric ions on struvite precipitation: A new assessment based on quantitative X-ray diffraction analysis. Water Res., 95, 310-318.

Yetilmezsoy, K., \& Sapci-Zengin, Z. (2009). Recovery of ammonium nitrogen from the effluent of UASB treating Poultry manure wastewater by MAP Precipitation as a slow release fertilizer. J. Hazard. Mater, 166(1), 260-269.

Zhou, K., Barjenbruch, M., Kabbe, C., Inial, G., \& Remy, C. (2016). Phosphorus recovery from municipal and fertilizer wastewater: China's potential and Perspective. Journal of Environmental Sciences, 52, 151-159. 